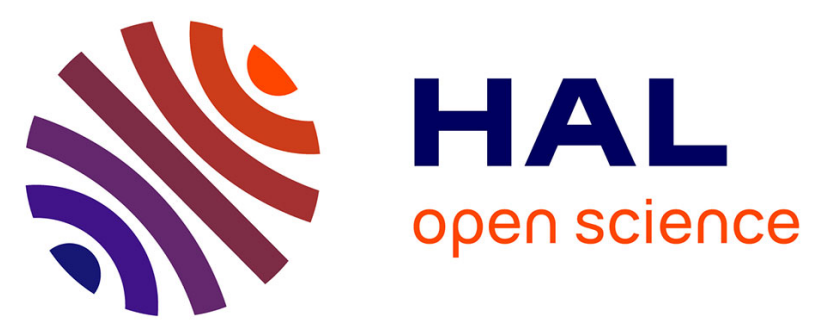

\title{
Anastrozole and letrozole: an investigation and comparison of quality of life and tolerability
}

J. Michael Dixon, Lorna Renshaw, Carolyn Langridge, Oliver E. Young, Mary

Mchugh, Linda Williams, Juliette Murray, E. Jane Macaskill, Fiona Mccaig, Oliver M. Dixon, et al.

\section{To cite this version:}

J. Michael Dixon, Lorna Renshaw, Carolyn Langridge, Oliver E. Young, Mary Mchugh, et al.. Anastrozole and letrozole: an investigation and comparison of quality of life and tolerability. Breast Cancer Research and Treatment, 2010, 125 (3), pp.741-749. 10.1007/s10549-010-1091-9 . hal-00574006

\section{HAL Id: hal-00574006 https://hal.science/hal-00574006}

Submitted on 7 Mar 2011

HAL is a multi-disciplinary open access archive for the deposit and dissemination of scientific research documents, whether they are published or not. The documents may come from teaching and research institutions in France or abroad, or from public or private research centers.
L'archive ouverte pluridisciplinaire HAL, est destinée au dépôt et à la diffusion de documents scientifiques de niveau recherche, publiés ou non, émanant des établissements d'enseignement et de recherche français ou étrangers, des laboratoires publics ou privés. 
Anastrozole and letrozole: an investigation and comparison of quality of life and tolerability

\author{
J. Michael Dixon ${ }^{1}$; Lorna Renshaw ${ }^{1}$; Carolyn Langridge ${ }^{2}$; Oliver E. Young ${ }^{1}$, Mary \\ McHugh $^{1}$; Linda Williams ${ }^{3}$; Juliette Murray ${ }^{1}$; E. Jane Macaskill ${ }^{1}$; Fiona McCaig ${ }^{1}$; Oliver \\ M. Dixon ${ }^{1}$; Lesley J Fallowfield ${ }^{2}$ \\ ${ }^{1}$ Edinburgh Breast Unit, Western General Hospital, Edinburgh, United Kingdom; ${ }^{2}$ Cancer \\ Research UK Psychosocial Oncology Group, University of Sussex, United Kingdom; ${ }^{3}$ Public \\ Health Sciences, University of Edinburgh, Medical School, Teviot Place, Edinburgh
}

Corresponding author:

J. Michael Dixon, MD; Edinburgh Breast Unit; Western General Hospital;

Edinburgh EH4 2XU, UK; Tel: 0131537 2907; Fax: 0131537 2653; e-mail: jmd@ed.ac.uk.

This is original work performed in the Edinburgh Breast Unit. It has been presented in abstract form and in presentations at the San Antonio Breast Cancer Conferences. 


\begin{abstract}
Purpose Previous studies have demonstrated that both anastrozole and letrozole are well tolerated. Letrozole suppresses estrogen to a greater degree than anastrozole in the serum and breast tumor. Concerns have been raised that greater potency may adversely affect patients' quality of life (QOL). Patients and Methods One hundred eighty-one postmenopausal women with invasive estrogen receptor-positive breast cancers were randomized to receive either 12 weeks of letrozole followed by 12 weeks of anastrozole or the reverse sequence. One hundred six received immediate adjuvant aromatase inhibitors (AIs) following surgery, and 75 received extended adjuvant therapy. The Functional Assessment of Cancer Therapy Endocrine Subscale (FACT-B-ES) QOL questionnaires were completed to assess QOL on each drug. Additional side-effect profiles were collected. Each patient completed a patient preference form. Results Twenty-one patients withdrew before study end, 10/179 (5.6\%) while taking letrozole and 4/173 $(2.3 \%)$ while taking anastrozole $(P=0.12)$. Tamoxifen-naïve patients had a higher mean ES score at entry versus those having extended therapy $(66.0$ vs. $61.9 ; P=0.001)$. There was no significant change in FACT-B-ES (overall) scores or ES (endocrine symptoms subscale) scores while patients were taking anastrozole or letrozole and no significant differences between drugs. Nearly $80 \%$ of patients reported one or more side effects with either agent. No differences in frequency, grade, or range of side effects were seen between drugs. Of 160 patients, 49 (30.6\%) preferred letrozole, $57(35.6 \%)$ preferred anastrozole, and $54(33.8 \%)$ had no preference $(P=$ 0.26, Pearson's chi-squared test). Conclusion Both AIs are equally well tolerated. There were no significant differences in QOL scores between the two drugs.
\end{abstract}

Keywords: Anastrozole • Breast cancer $\bullet$ Letrozole $・$ Quality of life $・$ Tamoxifen 


\section{Introduction}

Third-generation aromatase inhibitors (AIs) are approved as adjuvant endocrine therapy for postmenopausal women (PMW) with hormone-sensitive breast cancer [1]. The AIs include two broad categories, the reversible nonsteroidal agents, anastrozole and letrozole, and the irreversible steroidal inhibitor, exemestane [2]. These endocrine therapies have been developed to increase efficacy while decreasing the toxicities associated with more traditional estrogen receptor modulators (e.g., tamoxifen). AIs have been shown to improve disease-free survival (DFS) compared with tamoxifen [2]. Given this obvious benefit, the question of which AI to use is important.

Anastrozole and letrozole are now both widely used as adjuvant therapy in the treatment of breast cancer [3,4]. While previous studies have demonstrated that both of these agents are well tolerated [3, 5-7], there are reported differences in the potency of estrogen suppression between these agents. Studies have consistently demonstrated that letrozole reduces plasma estradiol and estrone sulfate levels to a significantly greater extent than does anastrozole [8-10]. Direct head-to-head trials of AIs are ongoing and will determine the extent to which these differences in potency translate into differences in clinical efficacy. The MA.27 trial is comparing event-free survival in PMW with receptor-positive primary breast cancer treated with anastrozole or exemestane following surgery (ClinicalTrials.gov identifier: NCT00066573), and the Femara Anastrozole Clinical Evaluation trial compares DFS in PMW with hormone receptorpositive $(\mathrm{HR}+)$, node-positive breast cancer treated with anastrozole or letrozole following surgery (ClinicalTrials.gov identifier: NCT00248170).

Indirect information from available large-scale trials comparing AIs with tamoxifen indicates that there are differences in clinical efficacy between AIs. Initial adjuvant therapy with 
AIs has been examined in the Arimidex, Tamoxifen Alone or in Combination (ATAC), Breast International Group 1-98, and the Tamoxifen, Exemestane Adjuvant Multicenter (TEAM) trials. In terms of efficacy, both anastrozole and letrozole have been shown to improve DFS compared with tamoxifen in patients with HR+ disease, although only letrozole significantly reduced early (at 2 years) distant metastases $(\mathrm{DM})$ events in this population (hazard ratio $[\mathrm{HR}] 0.73, P=0.001$ ) [3]. A significant reduction in DM events was seen with anastrozole in the HR+ patients but only at 100 months of follow-up [4]. The early improvement in DM events with letrozole has resulted in what appears to be an improvement in overall survival in patients taking letrozole compared with those on tamoxifen [11]. No improvement in survival has emerged from the ATAC study (HR 0.97, $P=0.7$ ) [4]. In the ongoing TEAM study, the first planned analysis at 2.75 years failed to demonstrate a significant difference between exemestane and tamoxifen with respect to DFS, although there was a reduction in breast cancer events (exemestane:tamoxifen, HR 0.89, $P$ $=0.12)[12]$.

Patient tolerability and its potential influence on adherence and therapeutic outcome are an important concern [13]. As a class, all AIs are reported to have similar toxicity profiles [3, 57]; however, the adjuvant AI trials are not directly comparable because of differences in trial design, particularly with regard to the time at which AI treatment commenced and the variable methods used to collect safety and tolerability data. In the absence of direct comparative data, it is not clear whether the greater activity/potency of letrozole might translate into greater effects on a patient's quality of life (QOL). Differences between agents in terms of QOL and tolerability are likely to be important when selecting the optimal therapy for individual patients. QOL assessments are useful for the clinician to make informed treatment decisions and to identify supportive interventions that improve tolerability and adherence. The aim of this study was to 
compare the effects of anastrozole and letrozole on patient tolerability and QOL as assessed by the Functional Assessment of Cancer Therapy - Breast - Endocrine Symptoms (FACT-B-ES, version 4) questionnaire and to determine if there is a patient preference for one agent over the other. Other aims, which are reported elsewhere, were to assess the effects of these two drugs on hormone levels and on markers of bone metabolism.

\section{Methods}

Study design

The Anastrozole versus Letrozole: Investigation into Quality of Life and Tolerability (ALIQUOT) study was an open-label crossover study of PMW with estrogen receptor-positive breast cancer receiving adjuvant AI therapy [9]. The ALIQUOT study examined the tolerability and side-effect profile associated with anastrozole and letrozole. One hundred eighty-five patients were randomized as part of their adjuvant endocrine therapy to receive either 12 weeks of letrozole followed by 12 weeks of anastrozole or 12 weeks of anastrozole followed by 12 weeks of letrozole. Assignment to treatment order was by randomized permuted blocks, undertaken manually using tables of random permutations. This crossover strategy was designed to allow direct comparison of anastrozole and letrozole in the same patient. Three patients withdrew before taking any drugs, and one patient withdrew because she was found to be premenopausal; therefore, a total of 181 patients were enrolled in the study and took one or the other drug. The current analysis was a limited-duration study comparing QOL, tolerability, and morbidity. The study was approved by the Lothian Research Ethics Committee in August 2003 and was conducted to comply with the principles laid down in the Declaration of Helsinki. 


\section{Assessments}

\section{Patient self-report}

FACT-B-ES (version 4) QOL questionnaires were completed at trial entry, after 4 weeks, and after 12 weeks of each drug. FACT-B is a 38-item questionnaire with six subscales assessing physical, social, emotional, and functional well-being, relationship with doctor, and additional concerns more specific to women with breast cancer. The FACT-B has a 5-point Likert-type response scale ranging from 0 to $4(0=$ not at all, $1=$ a little bit, $2=$ somewhat, $3=$ quite a bit, and 4 = very much). The ES assesses endocrine side effects and comprises 18 items designed for use with the FACT-B $[14,15]$. FACT-B-ES is the combined total of the FACT-B and the ES subscale scores.

\section{Nurse interview}

Graded adverse events (AEs) were collected using Common Terminology Criteria for Adverse Events (version 3.0) as reported directly by patients to study nurses at 1 month (by telephone), 2 months (by telephone), 3 months (at follow-up for trial), 4 months (by telephone), 5 months (by telephone), and 6 months (at trial follow-up), and for those receiving extended adjuvant therapy, at 9 months (at trial follow-up). At the end of the 24-week study period, each patient completed a patient preference form, which indicated drug preference and reasons for preference.

\section{Statistical methods}

Planned sample size

The typical standard deviation between patients using the FACT-B-ES QOL scale (the primary outcome) is 18 . In order to have $80 \%$ power to detect a difference of 4 units between paired treatments, a sample size of 160 was required. As there was likely to be patient dropout, the sample size was increase by another $20(12.5 \%)$ to allow for this. 


\section{Statistical testing}

The primary outcome of QOL (FACT-B-ES) was analyzed by Student's t-test for the comparison of baseline data, and by paired t-test for the change from baseline at 3 and 6 months. Both tests were two-sided. The secondary outcomes of patient-reported side effects and individual patient preference were compared by McNemar's test of paired data and chi-squared test, respectively. Patients who withdrew following the first period were included in the comparisons of change to 3 months but excluded from the 6-month analysis and the paired analyses of side effects. Sufficient additional patients were recruited to ensure that the number available for analysis would still exceed 160, at a level of attrition of $5 \%$ every 3 months.

\section{Results}

Patients/demographics

A total of 181 women (excluding a woman subsequently found to be premenopausal) participated in the study and received at least one dose of trial medication (Table 1). Patients were recruited into the QOL study from November 24, 2003 to April 11, 2006 from the Edinburgh Breast Unit and Queen Margaret Hospital Breast Unit, Dunfermline. One hundred six received immediate adjuvant AIs following surgery, and 75 received extended adjuvant AI therapy following the completion of 5 years of adjuvant tamoxifen treatment. Thirty-eight patients received chemotherapy post surgery before receiving tamoxifen. Eighty-nine patients received letrozole therapy for 3 months followed by anastrozole therapy for 3 months. Ninetytwo patients received the reverse sequence: 3 months of anastrozole followed by 3 months of letrozole. The mean age of patients was 63 years (range, 40 to 87 years), the mean height was $161 \mathrm{~cm}$ (range, 128 to $183 \mathrm{~cm}$ ) and the mean weight was $72.8 \mathrm{~kg}$ (range, 48.0 to $140.0 \mathrm{~kg}$ ). 


\section{Withdrawal rates}

Although both drugs were well tolerated, there were withdrawals for drug-associated reasons; these included joint pain and nausea associated with anastrozole treatment and hot flushes, joint pain, tiredness, headache, hair thinning, and blurred vision associated with letrozole treatment. A total of 21 patients withdrew before study end. Ten of $179(5.6 \%)$ withdrew while taking letrozole, and $4 / 173(2.3 \%)$ withdrew while taking anastrozole $(P=0.12)$. Withdrawals were not related to drug sequence. Two women withdrew following vaginal bleeding after finishing tamoxifen and before starting letrozole. Similarly, two women withdrew when bleeding developed after the completion of tamoxifen and before the start of anastrozole (Fig. 1). When using the FACT-B questionnaire, if there is a missing item in a scale, then an overall score cannot be produced.

QOL scores and endocrine subscale results of the FACT-B-ES scores Baseline scores for FACT-B-ES (overall quality of life score which is an additive of the FACT-B and the Endocrine Subscale Score) were 183.6 ( $n=92$; $95 \%$ confidence interval [CI], 179.4187.8) for tamoxifen-naïve patients and $185.4(n=74 ; 95 \% \mathrm{CI}, 181.6-189.3)(P=0.54)$ for patients on prior tamoxifen. Mean changes in FACT-B-ES scores from baseline are shown in Table 2. Mean changes from baseline were recorded at 3 and 6 months. An increase in score indicates a better overall QOL. There was no significant change in overall FACT-B-ES score or endocrine symptoms subscale (ES) score while patients were taking anastrozole or letrozole, and no significant differences between the two drugs were observed. Neither AI had any measureable detrimental effect on overall QOL. Neither the drug sequence nor prior tamoxifen treatment had any influence on the results. 
Endocrine Subscale scores for patients were subdivided by whether they had previously taken 5 years of tamoxifen. Tamoxifen-naïve patients had a mean ES score at entry of 66.0, compared with a score of 61.9 for those patients who had received prior tamoxifen $(P=0.001)$. The mean changes in ES scores from baseline are shown in Table 3 (an increase in score corresponds to fewer endocrine-related symptoms). There was a small but non-significant reduction in score in tamoxifen-naïve patients and a small but non-significant increase in score in patients who received prior tamoxifen therapy (A clinically meaningful score on the ES subscale is approximately 0.3 per item; with 18 items, this will be approximately 5). Overall, regardless of the sequence or prior tamoxifen, neither anastrozole nor letrozole significantly affected ES scores.

Side effect/symptom analysis

The percentages of patients with any reported side effect at any time are shown in Table 4 . Reporting of side effects was similar for both drugs after the initial 12 weeks of treatment. There were no significant differences in the frequency or range of side effects between anastrozole and letrozole. Nearly $80 \%$ of patients complained of one or more side effects with either anastrozole or letrozole. Joint pain occurred with the highest frequency (from 40-52\% depending upon the agent and previous tamoxifen exposure). Of the reported events of joint pain, 19-29\% of patients experienced grade $\geq 2$ pain. Hot flushes, lack of energy, and night sweats were also commonly reported by patients in both treatment arms. Table 5 reports the numbers of women with either no side effects or minimal (grade 1)/none on anastrozole or letrozole. Prior tamoxifen treatment did not significantly influence the reporting of side effects. When minimal (grade 1) side effects were excluded, this result did not change (Table 5). 
Given the possibility that symptoms may increase or decrease over time irrespective of drug treatment, comparisons of first- and second-period side effects were performed. Only the number of hot flushes (more in the first period; $P=0.0009$ ), joint problems (more in the second period; $P<0.0001$ ), and rashes (more in the first period; $P=0.003$ ) were influenced by time period. This result was found whether letrozole or anastrozole data were analyzed individually. These differences and the direction of the differences were still present when the subgroup of patients who had taken anastrozole first were analyzed $(P=0.0164,0.0009$, and 0.0253 , respectively) or when the subgroup of patients who had taken letrozole first were analyzed ( $P=$ $0.02,<0.0001$, and $=0.046$, respectively). This implies that the time period rather than the drug treatment is more of an influence on the presence of side effects and indicates that certain side effects take time to develop or improve.

\section{Patient preference questionnaires}

One hundred sixty patients completed a drug preference questionnaire. Forty-nine (30.6\%) preferred letrozole, 57 (35.6\%) preferred anastrozole, and 54 (33.8\%) had no preference. These results indicate that more than two thirds of women have a preference for one or the other AI. Drug order and previous tamoxifen exposure had no effect on preference. Figure 2 (online) presents the comparison of patient preferences according to previous tamoxifen use. There was no statistically significant preference in any group for any drug. Preferences were based on factors such as generally felt better, fewer hot flushes, less joint pain, less nauseated, less stomach upset, less tired, less depression, less emotional, less flatulence, less vaginal dryness, less abdominal bloating, less hair thinning, less weight gain, and less increased appetite. Table 6 gives patients' reasons for preferring letrozole or anastrozole. 


\section{Discussion}

The impact on patient QOL is an important consideration in the treatment of breast cancer. Since current treatment recommendations are based upon efficacy results from $\geq 5$ years of therapy, it is vital for the clinician to appreciate the long-term impact on QOL parameters over the same timeframe. Deterioration in these parameters may affect adherence and, in turn, have a negative impact on overall treatment outcome. Patients should be able to actively participate in the selection of therapy, weighing the clinical benefit against the side-effect profile and impact on QOL. Regular and standardized QOL assessments will ensure that both the clinician and patient have enough information to make informed decisions about treatment intervention.

Sub-protocol assessments of patients' QOL are being incorporated into increasing numbers of breast cancer trials. To date, QOL sub-analyses have been included in trials comparing AI therapy with tamoxifen (the Intergroup Exemestane Study [IES], ATAC, the National Surgical Adjuvant Study of Breast Cancer [NSAS BC] 03, and the TEAM trial NSAS BC 01 sub-study) and in trials comparing AIs with placebo (MA.17) [16-23]. In general, the majority of results from these trials suggest that the superior efficacy benefits of AIs over tamoxifen are achieved without compromising overall QOL in the short term [16, 18, 20-24].

It has been well established that tamoxifen is associated with some potentially lifethreatening AEs, while the third-generation AIs are associated with more predictable, manageable, and preventable side effects $[3,4,16-18,20,21,25]$. This more favorable tolerability profile should translate into an improved impact on a patient's overall QOL, but there are adherence issues with AIs, and significant numbers of patients discontinue therapy because of side effects. This is potentially very worrying, because some symptoms, especially vasomotor symptoms and arthralgias, have been shown to be associated with better outcomes [26]. Given 
the lack of direct head-to-head comparisons of different AIs and their impact on QOL, it is difficult for clinicians to make evidence-based decisions when choosing an AI. The results presented here compare anastrozole and letrozole directly in the same patients and assess the effects of these AIs on QOL. This design has significant advantages over comparing groups of women, as it removes a major variable, the patient. Despite the reported greater potency of letrozole, it was as well tolerated as anastrozole, and neither drug had a significant impact on overall QOL. Although patients who completed treatment had little if any measured impact on QOL, side effects with both drugs were common and were reported by $80 \%$ of women. These side effects were identical with both drugs and represent a class effect of AIs rather than effects that are limited/restricted to a specific drug. Most patients had a definite preference for either anastrozole or letrozole, with similar numbers of patients preferring each agent.

A similar crossover study by Thomas et al. comparing anastrozole and letrozole in women with breast cancer $(\mathrm{N}=72)$ showed that a patient's preference for either anastrozole or letrozole was related to the patient's adverse events and QOL while taking the drug [27]. In contrast to the current study, which showed similar results for both drugs, the study by Thomas et al. showed that significantly more women chose letrozole, which was associated with significantly fewer adverse events and a significantly better QOL compared with anastrozole [27].

This study has several limitations. It was an open-label, single-institution design with short follow-up and limited patient numbers, and patient reporting is potentially subject to influence from family/friends, support groups, and publically available medical information. Anastrozole is the most widely and frequently used AI in the United Kingdom, and potential social influences for preference must be considered. Despite these limitations and potentially 
confounding variables, the data reported here provide a useful framework within which physicians and patients can make informed decisions about initial adjuvant or extended adjuvant AI therapy. Larger-scale analyses in direct comparator trials will be required to confirm the current findings, but such studies have their own limitations. While treatment decisions cannot be made solely on the basis of QOL and reported side-effect profiles, such assessments are an important consideration, as adherence is likely to be significantly affected by a drug's impact on these parameters. 


\section{Acknowledgments}

Financial support for medical editorial assistance was provided by Novartis Pharmaceuticals.

We thank Maria Soushko, PhD, of Phase Five Communications Inc. for medical editorial assistance with this manuscript.

Financial support for this study was provided by Novartis Oncology. 


\section{References}

1. Cazzaniga ME, Mustacchi G, Pronzato P, De Matteis A, Di Costanzo F, Floriani I; on behalf of the NORA Study Group (2007) Adjuvant treatment of early breast cancer: do the St. Gallen recommendations influence clinical practice? Results from the NORA study. Ann Oncol 18:1976-1980

2. Eisen A, Trudeau M, Shelley W, Messersmith H, Pritchard KI (2008) Aromatase inhibitors in adjuvant therapy for hormone receptor positive breast cancer: a systemic review. Cancer Treat Rev 34:157-174

3. Thürlimann B, Keshaviah A, Coates AS, et al; The Breast International Group (BIG) 1-98 Collaborative Group (2005) A comparison of letrozole and tamoxifen in postmenopausal women with early breast cancer. N Engl J Med 353:2747-2757

4. Forbes JF, Cuzick J, Buzdar A, Howell A, Tobias JS, Baum M; Arimidex, Tamoxifen, Alone or in Combination (ATAC) Trialists' Group (2008) Effect of anastrozole and tamoxifen as adjuvant treatment for early-stage breast cancer: 100-month analysis of the ATAC trial. Lancet Oncol 9:45-53

5. Coates AS, Keshaviah A, Thurlimann B, et al (2007) Five years of letrozole compared with tamoxifen as initial adjuvant therapy for postmenopausal women with endocrine-responsive early breast cancer: update of study BIG 1-98. J Clin Oncol 25:486-492

6. Buzdar A, Howell A, Cuzick J, et al; the Arimidex, Tamoxifen, Alone or in Combination Trialists' Group (2006) Comprehensive side-effect profile of anastrozole and tamoxifen as adjuvant treatment for early-stage breast cancer: long-term safety analysis of the ATAC trial. Lancet Oncol 7:633-643 
7. Goss PE, Ingle JN, Martino S, et al (2005) Randomized trial of letrozole following tamoxifen as extended adjuvant therapy in receptor-positive breast cancer: updated findings from NCIC CTG MA.17. J Nat Cancer Inst 97:1262-1271

8. Geisler J, Haynes B, Anker G, Dowsett M, Lonning PE (2002) Influence of letrozole and anastrozole on total body aromatization and plasma estrogen levels in postmenopausal breast cancer patients evaluated in a randomized, cross-over study. J Clin Oncol 20:751-757

9. Dixon JM, Renshaw L, Young O, et al (2008) Letrozole suppresses plasma estradiol and estrone sulphate more completely than anastrozole in postmenopausal women with breast cancer. J Clin Oncol 26:1671-1676

10. Geisler J, Helle H, Ekse D, et al (2008) Letrozole is superior to anastrozole suppressing breast cancer tissue and plasma estrogen levels. Clin Cancer Res 14:6330-6335

11. BIG 1-98 Collaborative Group, Mouridsen H, Giobbie-Hurder A, Goldhirsch A, et al (2009) Letrozole therapy alone or in sequence with tamoxifen in women with breast cancer. $\mathrm{N}$ Engl J Med 361:766-776

12. Jones SE, Seynaeve C, Hasenburg A, et al (2009) Results of the first planned analysis of the TEAM (tamoxifen exemestane adjuvant multinational) prospective randomized phase III trial in hormone sensitive postmenopausal early breast cancer. Cancer Res 69(2 suppl):67s: Abstract 15

13. Fallowfield L (2008) There's many a slip twixt cup and lip: adherence issues in cancer therapy. Nat Clin Pract Oncol 5:118-119

14. Brady MJ, Cella DF, Mo F, et al (1997) Reliability and validity of the Functional Assessment of Cancer Therapy-Breast quality-of-life instrument. J Clin Oncol 15:974-986 
15. Fallowfield LJ, Leaity S, Howell A, Benson S, Cella D (1999) Assessment of quality of life in women undergoing hormonal therapy for breast cancer: Validation of an endocrine subscale for the FACT-B. Breast Cancer Res Treat 55:189-199

16. Fallowfield LJ, Bliss JM, Porter LS, et al: Quality of life in the intergroup exemestane study: a randomized trial of exemestane versus continued tamoxifen after 2 to 3 years of tamoxifen in postmenopausal women with primary breast cancer. J Clin Oncol 24:910-917, 2006

17. Fallowfield L, Cella D, Cuzick J, et al (2004) Quality of life of postmenopausal women in the Arimidex, Tamoxifen, Alone or in Combination (ATAC) Adjuvant Breast Cancer Trial. J Clin Oncol 22:4261-4271

18. Cella D, Fallowfield L, Barker P, Cuzick J, Locker G, Howell A; ATAC Trialists Group (2006) Quality of life of postmenopausal women in the ATAC ("Arimidex", tamoxifen, alone or in combination) trial after completion of 5 years' adjuvant treatment for early breast cancer. Breast Cancer Res Treat 100:273-284

19. Ohsumi S, Shimozuma K, Ohashi Y, Nomura Y, Aihara T, Takatsuka Y (2009) Healthrelated quality-of-life and psychological distress of postmenopausal breast cancer patients after surgery during the randomized trial, N-SAS BC 03, comparing further tamoxifen with switching to anastrozole after adjuvant tamoxifen for 1 to 4 years: the final results. Cancer Res 69(2 suppl):145s-146s: Abstract 1136

20. Whelan TJ, Goss PE, Ingle JN, et al (2005) Assessment of quality of life in MA.17: a randomized, placebo-controlled trial of letrozole after 5 years of tamoxifen in postmenopausal women. J Clin Oncol 23:6931-6940 
21. Abetz L, Barghout V, Thomas S, Arbuckle R (2005) Letrozole did not worsen quality of life relative to placebo in post-menopausal women with early breast cancer: results from the US subjects of the MA-17 study.94(suppl 1):A100: Abstract 2047

22. Muss HB, Tu D, Ingle JN, et al (2008) Efficacy, toxicity, and quality of life in older women with early-stage breast cancer treated with letrozole or placebo after 5 years of tamoxifen: NCIC CTG Intergroup Trial MA.17. J Clin Oncol 26:1956-1964

23. Takei H, Ohsumi S, Shimozuma K, et al (2006) Health-related quality of life and psychological distress of breast cancer patients after surgery during phase III randomized trial comparing tamoxifen, exemestane, and anastrozole: N-SAS BC 04. Breast Cancer Res Treat 100(suppl 1):S189: Abstract A4054

24. Coombes RC, Kilburn LS, Snowdon CF, et al; Intergroup Exemestane Study (2007) Survival and safety of exemestane versus tamoxifen after 2-3 years' tamoxifen treatment (Intergroup Exemestane Study): a randomised controlled trial. Lancet 369:559-570. Erratum in: (2007) Lancet 369:906

25. Howell A, Cuzick J, Baum M, et al; ATAC Trialists' Group (2005) Results of the AT AC (Arimidex, Tamoxifen, Alone or in Combination) trial after completion of 5 years' adju vant treatment for breast cancer. Lancet 365:60-62

26. Cuzick J, Sestak I, Cella D, Fallowfield L; ATAC Trialists' Group (2008) Treatment emergent endocrine symptoms and the risk of breast cancer recurrence: a retrospective analysis of the ATAC trial. Lancet Oncol 9:1143-1148

27. Thomas R, Godward S, Makris A, Bloomfield D, Moody AM, Williams M (2004) Giving patients a choice improves quality of life: a multi-centre, investigator-blind, randomised, 
crossover study comparing letrozole with anastrozole. Clin Oncol (R Coll Radiol) 16:485491 
Table 1 Baseline demographic and medical characteristics

\begin{tabular}{|c|c|c|c|}
\hline Characteristic & Total & A to $\mathrm{L}$ & L to $\mathrm{A}$ \\
\hline $\mathrm{N}$ & 181 & 92 & 89 \\
\hline \multicolumn{4}{|l|}{ Adjuvant AI treatment } \\
\hline Immediate, $n$ & $106(59)$ & $53(58)$ & $53(60)$ \\
\hline \multicolumn{4}{|l|}{$(\%)$} \\
\hline Extended, $n(\%)$ & $75(42)$ & $39(42)$ & $36(40)$ \\
\hline \multirow[t]{3}{*}{ Age (years) } & Mean: 63.6 & Mean: 63.0 & Mean: 64.2 \\
\hline & Median: 64 & Median: 63 & Median: 64 \\
\hline & Range: $41-87$ & Range: $41-84$ & Range: $41-87$ \\
\hline \multirow[t]{3}{*}{ Height $(\mathrm{cm})$} & Mean: 161.19 & 160.34 & 162.07 \\
\hline & Median: 161.3 & 160.2 & 161.5 \\
\hline & Range: $128-182.9$ & $(130-179.2)$ & $(128-182.9)$ \\
\hline \multirow[t]{3}{*}{ Weight (kg) } & Mean: 72.86 & 71.95 & 73.8 \\
\hline & Median: 69.9 & 69.7 & 70.2 \\
\hline & Range: $48-140$ & $48-138$ & $50-140$ \\
\hline \multicolumn{4}{|l|}{ Tumor stage } \\
\hline $\mathrm{T} 1, n(\%)$ & $128(71 \%)$ & $66(72 \%)$ & $62(70 \%)$ \\
\hline $\mathrm{T} 2, n(\%)$ & $47(26 \%)$ & $23(25 \%)$ & $24(27 \%)$ \\
\hline $\mathrm{T} 3, n(\%)$ & $3(2 \%)$ & $2(2 \%)$ & $1(1 \%)$ \\
\hline $\mathrm{T} 4 \mathrm{~b}, n(\%)$ & $2(1 \%)$ & $1(1 \%)$ & $1(1 \%)$ \\
\hline $\mathrm{T} 4 \mathrm{~d}, n(\%)$ & $1(0.5 \%)$ & $0(0 \%)$ & $1(1 \%)$ \\
\hline
\end{tabular}

Nodal status 


\begin{tabular}{|c|c|c|c|}
\hline No, $n(\%)$ & $30(17 \%)$ & $15(16 \%)$ & $15(17 \%)$ \\
\hline $\mathrm{N} 1, n(\%)$ & $151(83 \%)$ & $77(84 \%)$ & $74(83 \%)$ \\
\hline $\begin{array}{l}\text { Prior chemotherapy, } \mathrm{n} \\
(\%)\end{array}$ & $38(21 \%)$ & $19(21 \%)$ & $19(21 \%)$ \\
\hline Prior HRT* ${ }^{*}$ n (\%) & $57(31 \%)$ & $28(30 \%)$ & $29(33 \%)$ \\
\hline
\end{tabular}


Table 2 Mean changes from baseline for the Functional Assessment of Cancer Therapy with Endocrine Subscale scores (FACT-B-ES) (overall quality of life score)

\begin{tabular}{|c|c|c|c|}
\hline Patient population & Drug sequence & Mean change from & Mean change from \\
\hline & & baseline at 3 months & baseline at 6 months \\
\hline All patients & Letrozole to & $1.3(n=67 ; 95 \% \mathrm{CI}$ & $0.2(n=67 ; 95 \% \mathrm{CI}$ \\
\hline \multirow[t]{3}{*}{$(\mathrm{N}=181)$} & anastrozole & $-2.2-4.8)^{*}$ & $-3.5-3.9)$ \\
\hline & Anastrozole to & $1.6(n=75 ; 95 \% \mathrm{CI}$ & $1.7(n=74 ; 95 \% \mathrm{CI}$ \\
\hline & letrozole & $-1.8-4.9)$ & $-1.8-5.2)$ \\
\hline Tamoxifen-naïve & Letrozole to & $0.7(n=39 ; 95 \% \mathrm{CI}$ & $0.5(n=38 ; 95 \% \mathrm{CI}$ \\
\hline \multirow[t]{3}{*}{ patients $(n=106)$} & anastrozole & $-4.1-5.6)$ & $-4.5-5.5)$ \\
\hline & Anastrozole to & $1.3(n=40 ; 95 \% \mathrm{CI}$ & $0.6(n=39 ; 95 \% \mathrm{CI}$ \\
\hline & letrozole & $-3.5-6.0)$ & $-4.4-5.5)$ \\
\hline Prior tamoxifen & Letrozole to & $2.1(n=28 ; 95 \% \mathrm{CI}$ & $-0.3(n=29 ; 95 \% \mathrm{CI}$ \\
\hline \multirow[t]{3}{*}{ patients $(n=75)$} & anastrozole & $-3.2-7.4)$ & $-6.0-5.5)$ \\
\hline & Anastrozole to & $1.9(n=35 ; 95 \% \mathrm{CI}$ & $2.9(n=35 ; 95 \% \mathrm{CI}$ \\
\hline & letrozole & $-2.8-6.7)$ & $2.3-8.2)$ \\
\hline
\end{tabular}

Abbreviation: CI, confidence interval.

*Numbers of patients with fully completed data at baseline and 3 months. 
Table 3 Mean changes in Endocrine Subscale (ES) scores from baseline

\begin{tabular}{|c|c|c|c|}
\hline \multirow[t]{2}{*}{ Patient population } & \multirow[t]{2}{*}{ Drug sequence } & \multirow{2}{*}{$\begin{array}{l}\text { Mean change from } \\
\text { baseline at } 3 \text { months }\end{array}$} & \multirow{2}{*}{$\begin{array}{l}\text { Mean change from } \\
\text { baseline at } 6 \text { months }\end{array}$} \\
\hline & & & \\
\hline \multirow[t]{4}{*}{ All patients } & Letrozole to & $-0.5(n=74 ; 95 \% \mathrm{CI}$ & $-0.7(n=72 ; 95 \% \mathrm{CI}$ \\
\hline & anastrozole & $-2.0-1.0)$ & $-2.2-0.9)$ \\
\hline & Anastrozole to & $-0.6(n=86 ; 95 \% \mathrm{CI}$ & $-0.1(n=80 ; 95 \%$ CI, \\
\hline & letrozole & $-2.0-0.8)$ & $-1.6-1.4)$ \\
\hline Tamoxifen-naïve & Letrozole to & $-1.1(n=45 ; 95 \% \mathrm{CI}$, & $-1.1(n=42 ; 95 \% \mathrm{CI}$, \\
\hline \multirow[t]{3}{*}{ patients $(n=106)$} & anastrozole & $-2.7-0.6)$ & $-3.0-0.8)$ \\
\hline & Anastrozole to & $-2.1(n=48 ; 95 \% \mathrm{CI}$ & $-1.6(n=44 ; 95 \% \mathrm{CI}$, \\
\hline & letrozole & $-3.7--0.5)$ & $-3.4-0.3)$ \\
\hline Prior tamoxifen & Letrozole to & $0.4(n=29 ; 95 \%$ CI & $-0.1(n=30 ; 95 \%$ CI, \\
\hline \multirow[t]{3}{*}{ patients $(n=75)$} & anastrozole & $-2.3-0.1)$ & $-2.7-2.6)$ \\
\hline & Anastrozole to & $1.3(n=38 ; 95 \% \mathrm{CI}$ & $1.7(n=36 ; 95 \% \mathrm{CI}$ \\
\hline & letrozole & $-1.1-3.7)$ & $-0.7-4.1)$ \\
\hline
\end{tabular}

Abbreviation: CI, confidence interval.

An increase in score indicates fewer symptoms.

$n=$ numbers of patients in each cell with complete data for analysis. 
Table 4 Side effects as reported directly by patients to study nurses

\begin{tabular}{|c|c|c|c|c|c|}
\hline Symptom & Group & $\begin{array}{l}\text { Anastrozole } \\
(\%) \text {, any* }\end{array}$ & $\begin{array}{l}\text { Letrozole } \\
(\%) \text {, any* }\end{array}$ & $\begin{array}{l}\text { Anastrozole } \\
(\%) \text { grade } \\
\geq 2^{\dagger}\end{array}$ & $\begin{array}{l}\text { Letrozole } \\
(\%) \text { grade } \\
\geq 2^{\dagger}\end{array}$ \\
\hline \multirow[t]{2}{*}{ Alopecia } & $\begin{array}{l}\text { Tamoxifen- } \\
\text { naïve }\end{array}$ & $3(3)$ & $4(4)$ & $3(3)$ & $1(1)$ \\
\hline & $\begin{array}{l}\text { Prior } \\
\text { tamoxifen }\end{array}$ & $2(3)$ & $3(3)$ & $0(0)$ & $0(0)$ \\
\hline \multirow[t]{2}{*}{ Depression } & $\begin{array}{l}\text { Tamoxifen- } \\
\text { naïve }\end{array}$ & $5(5)$ & $4(4)$ & $2(2)$ & $1(1)$ \\
\hline & $\begin{array}{l}\text { Prior } \\
\text { tamoxifen }\end{array}$ & $4(5)$ & $4(6)$ & $2(3)$ & $1(1)$ \\
\hline \multirow[t]{2}{*}{ Diarrhea } & $\begin{array}{l}\text { Tamoxifen- } \\
\text { naïve }\end{array}$ & $4(4)$ & $9(9)$ & $1(1)$ & $1(1)$ \\
\hline & $\begin{array}{l}\text { Prior } \\
\text { tamoxifen }\end{array}$ & $2(3)$ & $2(3)$ & $1(1)$ & $0(0)$ \\
\hline \multirow[t]{2}{*}{ Headaches } & $\begin{array}{l}\text { Tamoxifen- } \\
\text { naïve }\end{array}$ & $12(12)$ & $8(8)$ & $5(5)$ & $6(6)$ \\
\hline & $\begin{array}{l}\text { Prior } \\
\text { tamoxifen }\end{array}$ & $6(8)$ & $9(13)$ & $4(5)$ & $2(3)$ \\
\hline \multirow[t]{2}{*}{ Hot flushes } & $\begin{array}{l}\text { Tamoxifen- } \\
\text { naïve }\end{array}$ & $32(31)$ & $37(36)$ & $12(12)$ & $18(18)$ \\
\hline & Prior & $29(40)$ & $25(35)$ & $16(22)$ & $15(21)$ \\
\hline
\end{tabular}


tamoxifen

\begin{tabular}{|c|c|c|c|c|c|}
\hline \multirow[t]{2}{*}{ Irritability } & Tamoxifen- & $3(3)$ & $3(3)$ & - & - \\
\hline & \multicolumn{5}{|l|}{ naïve } \\
\hline & Prior & $0(0)$ & $3(4)$ & - & - \\
\hline & tamoxifen & & & & \\
\hline \multirow[t]{4}{*}{ Joint pain } & Tamoxifen- & $51(49)$ & $53(52)$ & $23(22)$ & $30(25)$ \\
\hline & naïve & & & & \\
\hline & Prior & $29(40)$ & $37(52)$ & $14(19)$ & $14(20)$ \\
\hline & tamoxifen & & & & \\
\hline \multirow[t]{4}{*}{ Joint stiffness } & Tamoxifen- & $6(6)$ & $2(2)$ & - & - \\
\hline & naïve & & & & \\
\hline & Prior & $2(3)$ & $0(0)$ & - & - \\
\hline & tamoxifen & & & & \\
\hline \multirow[t]{4}{*}{ Lack of energy } & Tamoxifen- & $15(14)$ & $25(25)$ & $1(1)$ & $5(5)$ \\
\hline & naïve & & & & \\
\hline & Prior & $14(19)$ & $6(8)$ & $3(4)$ & $1(1)$ \\
\hline & tamoxifen & & & & \\
\hline \multirow[t]{4}{*}{ Lightheaded/ } & Tamoxifen- & $4(4)$ & $6(6)$ & $0(0)$ & $3(3)$ \\
\hline & naïve & & & & \\
\hline & Prior & $4(5)$ & $5(7)$ & $0(0)$ & $0(0)$ \\
\hline & tamoxifen & & & & \\
\hline Nausea & Tamoxifen- & $9(9)$ & $6(6)$ & $1(1)$ & $1(1)$ \\
\hline
\end{tabular}




\begin{tabular}{|c|c|c|c|c|c|}
\hline & Prior & $2(3)$ & $4(6)$ & $0(0)$ & $0(0)$ \\
\hline & tamoxifen & & & & \\
\hline \multirow[t]{4}{*}{ Night sweats } & Tamoxifen- & $11(11)$ & $14(14)$ & $4(4)$ & $6(6)$ \\
\hline & naïve & & & & \\
\hline & Prior & $4(5)$ & $7(10)$ & $2(3)$ & $4(6)$ \\
\hline & tamoxifen & & & & \\
\hline \multirow{4}{*}{$\begin{array}{l}\text { Sleeping } \\
\text { difficulties }\end{array}$} & Tamoxifen- & $2(2)$ & $8(8)$ & $1(1)$ & $4(4)$ \\
\hline & naïve & & & & \\
\hline & Prior & $4(5)$ & $3(4)$ & $1(1)$ & $1(1)$ \\
\hline & tamoxifen & & & & \\
\hline \multirow{3}{*}{$\begin{array}{l}\text { Vaginal } \\
\text { discharge }\end{array}$} & Tamoxifen- & $1(1)$ & $0(0)$ & $1(1)$ & $0(0)$ \\
\hline & naïve & & & & \\
\hline & Prior & $1(1)$ & $2(3)$ & $0(0)$ & $1(1)$ \\
\hline
\end{tabular}

*Numbers in these columns represent the number of side effects of any grade during each 12 week treatment period.

${ }^{\dagger}$ Numbers in these columns represent the number of grade 2 side effects (graded using Common Terminology Criteria for Adverse Events Version 3.0) or higher reported at any time with either drug. 
Table 5 Side effects as reported directly by patients to study nurses subdivided by prior tamoxifen status

\begin{tabular}{llll}
\hline Symptom & Group & Anastrozole (\%) & Letrozole (\%) \\
\hline No side effects & Tamoxifen-naïve & $23(22)$ & $20(20)$ \\
& Prior tamoxifen & $10(14)$ & $25(35)$ \\
Minimal (grade 1) $/$ & Tamoxifen-naïve & $58(56)$ & $59(58)$ \\
no side effects & & & \\
& Prior tamoxifen & $48(65)$ & $34(48)$ \\
\hline
\end{tabular}

Numbers represent the number of any grade side effects during each 12 -week treatment period. 
Table 6 Patients' stated reason for drug preference

\section{Patient preference}

\begin{tabular}{lll}
\cline { 2 - 3 } Reason for preference & Letrozole & Anastrozole \\
\hline Generally felt better & $67 \%(16 / 24)$ & $94 \%(30 / 32)^{*}$ \\
Less tired & $29 \%(7 / 24)$ & $69 \%(22 / 32)^{\dagger}$ \\
Less sick & $29 \%(7 / 24)$ & $38 \%(12 / 32)$ \\
Less tummy upset & $29 \%(7 / 24)$ & $31 \%(10 / 32)$ \\
Fewer hot flushes & $33 \%(8 / 24)$ & $53 \%(17 / 32)$ \\
Fewer joint pains & $42 \%(10 / 24)$ & $50 \%(16 / 32)$ \\
\hline
\end{tabular}

$* P=0.009$.

${ }^{\dagger} P=0.003$. 
Fig 1. CONSORT diagram.

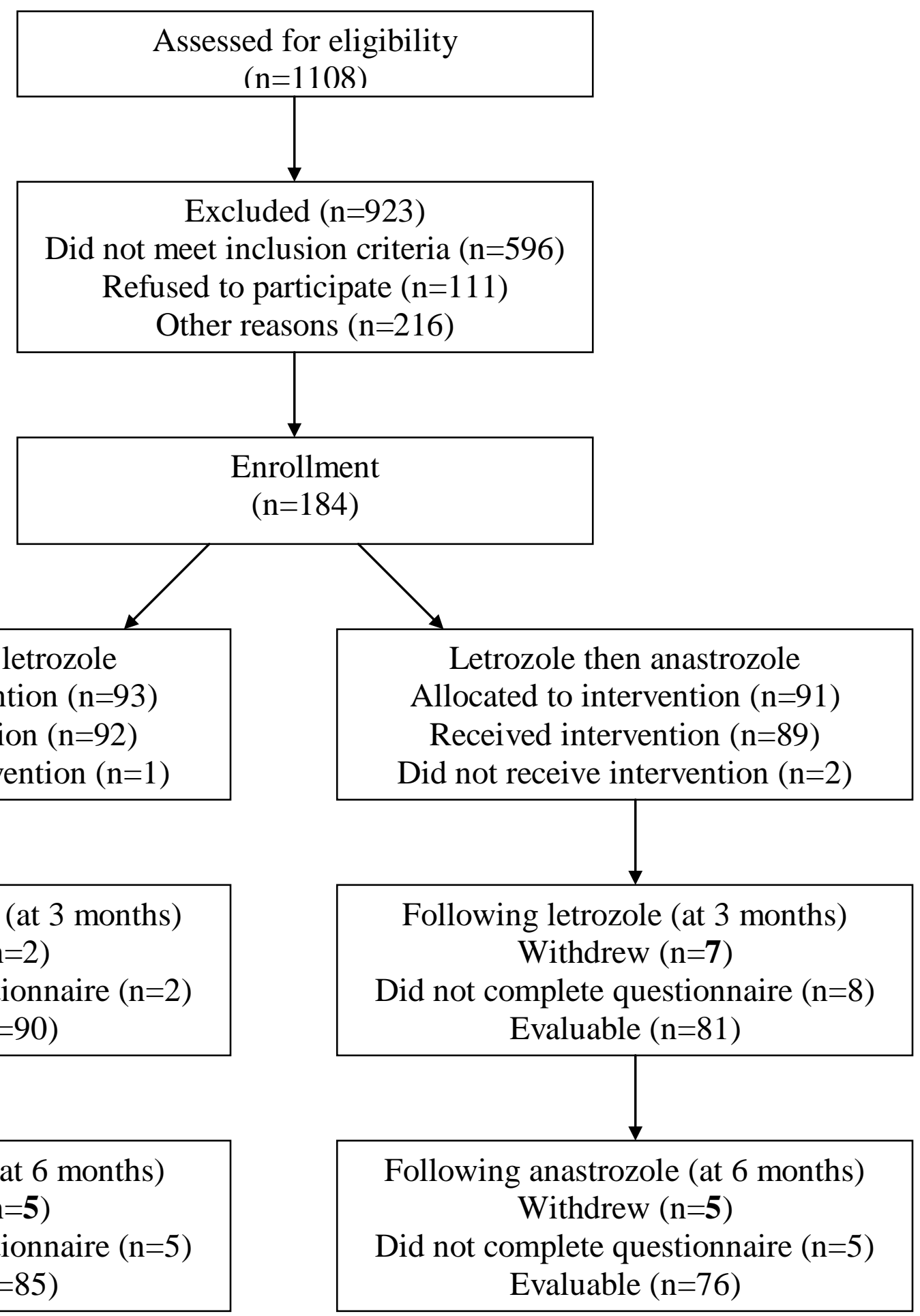


Fig 2. Results from the drug preference questionnaire (online only).

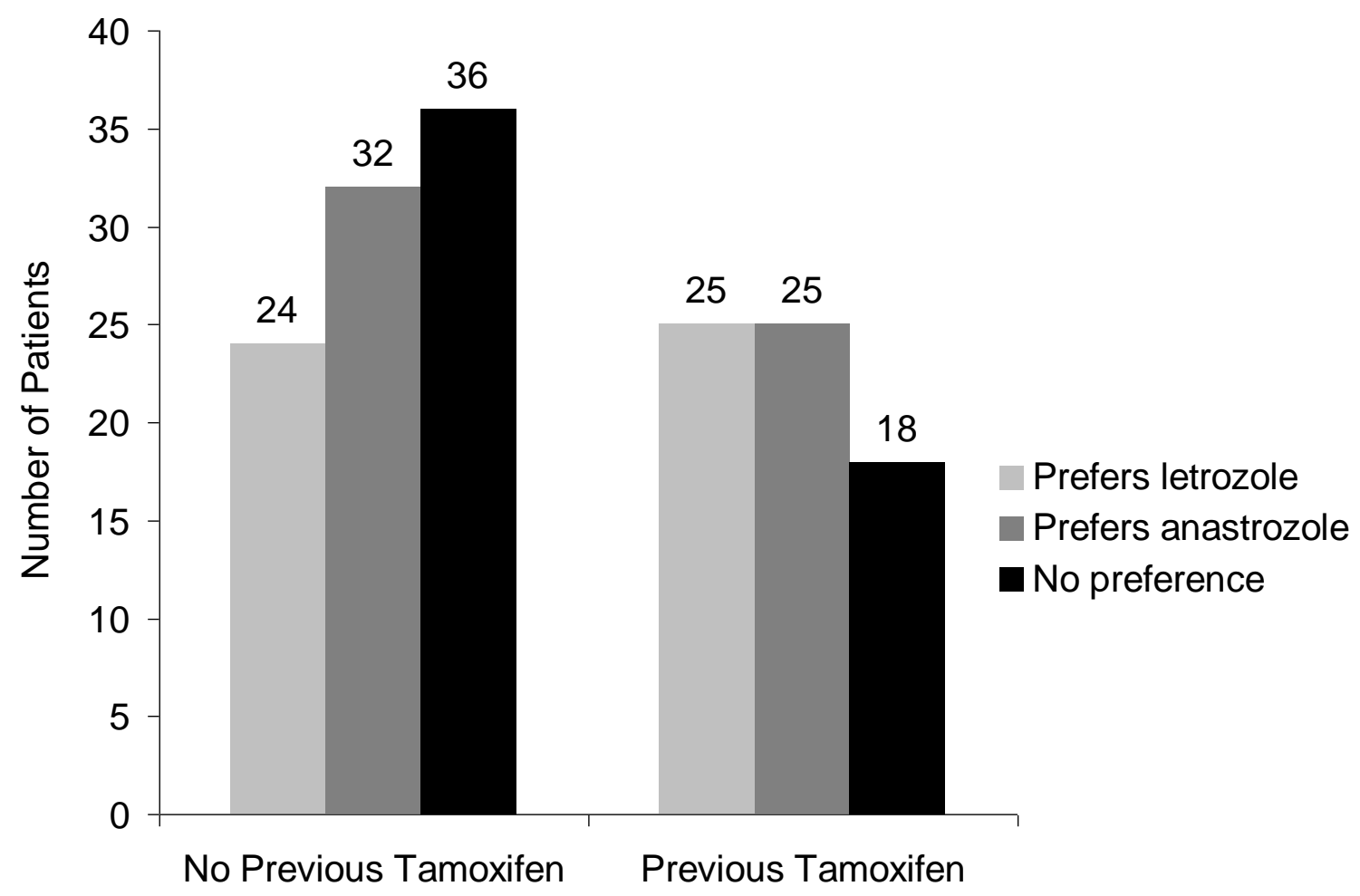

